\title{
Off-label use and harmful potential of drugs in a NICU in Brazil: A descriptive study
}

\author{
Alcidésio Sales de Souza $\mathrm{Jr}^{1,2,3^{*}}$, Djanilson Barbosa dos Santos ${ }^{4,5}$, Luís Carlos Rey ${ }^{6}$, Marina Garruti Medeiros ${ }^{4}$, \\ Marta Gonçalves Vieira ${ }^{7}$ and Helena Lutéscia Luna Coelho ${ }^{2,4}$
}

\begin{abstract}
Background: Neonates admitted to neonatal intensive care units (NICU) are exposed to a wide variety of drugs, most without any data on safety and efficacy. Objective: To describe the drugs prescribed to different groups of neonates hospitalized in a NICU, and to analyze off-label use and harmful potential of drugs, in terms of the potential risks.

Methods: This was a six-month retrospective cohort study of drug use in a NICU, with neonates who were inpatients for a period of over 24 hours, and using prescription data from electronic medical records. Drug information found in the package leaflets, in the British National Formulary for Children 2012-2013, and in the Thomson Micromedex database were compared. Drugs and excipients considered potentially harmful were evaluated according to the literature.
\end{abstract}

Results: One hundred ninety-two neonates were included in the study, with a mean gestational age (GA) of 33.3 weeks (SD \pm 4.3 ), $75.0 \%$ were preterm, with an average of 18.8 days of hospitalization (SD \pm 18.1 ), and a total of 3617 neonates-day. 3290 prescriptions were registered, on average 17.1 prescriptions/neonate (SD \pm 17.9$)$ and 8.8 drugs/neonate ( $S D \pm 5.9$ ). The number of prescriptions and drugs was higher in neonates with $G A<31$ weeks $(p<0.05)$. Anti-infectives for systemic use, blood, alimentary tract and metabolism drug groups were more frequent, varying according to the GA. Neonates (99.5\%) were exposed to unlicensed drugs (UL) and off label use $(\mathrm{OL})$, more frequently in $\mathrm{GA}<28$ weeks $(p<0.05)$. Most $\mathrm{OL}$ drugs used were indicated for newborns. 15 potentially harmful drugs were used in more than $70 \%$ of the neonates, and most were OL; exposure to harmful excipients occurred in $91.6 \%$ of the neonates, a percentage even higher when considering immature neonates.

Conclusions: Immature neonates in a Brazilian NICU are exposed to a variety of OL, UL and potentially harmful drugs and excipients.

Keywords: Off-label use, Unlicensed medicines, Harmful excipients, High-alert medications, Neonate, Drug

\section{Background}

Lack of scientific evidence is one of the main problems involved in using medicine among neonates, especially those in critical care. Less mature neonates, with a gestational age below 32 weeks, and those with low birth weight $(<2500 \mathrm{~g})$ are frequently affected by

\footnotetext{
* Correspondence: alcidesiojr@gmail.com

${ }^{1}$ Pharmacy Department, Mother and Child Hospital of Brasilia, Brasília, Federal District, Brazil

${ }^{2}$ Doctoral Program in Development and Technological Innovation in Drugs, Federal University of Ceará, Fortaleza, Ceará, Brazil

Full list of author information is available at the end of the article
}

apnea due to prematurity, neonatal encephalopathy, bronchopulmonary dysplasia and systemic infections. These problems explain the high use of drugs, which might reach 20 types concomitantly [1-3]. Almost $90 \%$ of this use is off-label (OL) or unlicensed (UL), and should be considered experimental and be registered and followed carefully [3].

Medicine is an important innovation that has contributed towards improving neonate survival over recent decades, but adverse consequences from their use cannot always be foreseen, either in the short term or in 
the long term, as some effects are unpredictable [4]. Some serious, adverse events have been correlated with drug exposure, such as gastrointestinal complications relating to tolazoline, and the grey baby syndrome has been related to chloramphenicol [3]. Recently, ranitidine therapy was recognized as being associated with an increased risk of infections, necrotizing enterocolitis (NEC), and has a fatal outcome in very low birth weight (VLBW) newborns, but this and other drugs, such as domperidone, meropenem and cephalosporins, remain in use, despite the controversy [5-7]. The limited existing knowledge on pharmacokinetic development, pharmacodynamics and dose determination in relation to neonates, in association with the scarcity of clinical trials, may make it a complex task to select the right medicine and establish doses for treating neonates $[4,8]$.

There is no standard profile of drug use for neonates in critical care, other than some efforts towards standardization, such as establishing local or general guidelines [9-11] and publications like handbooks [12] and formularies [13] that are distributed worldwide. Almost all the medicine used in neonatal intensive care units (NICUs) is administered intravenously, and depending on gestational age and birth weight, the drug group most used is antibiotics, followed by drugs for use in the respiratory and nervous systems [2, 14-16].

In Brazil, drugs are authorized by the regulatory agency Agência Nacional de Vigilância Sanitária (ANVISA) but there is not a specific policy for registration of pediatric or neonatal drugs. There are 841 NICUs in Brazil, with a total of 8432 hospital beds, and national guidelines for prescriptions in neonatology are available only in cases of congenital infections, neonatal resuscitation, sepsis, pain and jaundice [17]. Studies in Brazil have shown a 5.5 to $12.6 \%$ variation in UL use and 27.7 to $49.5 \%$ in OL drug use, mostly relating to antibiotics, analgesics and drugs used in the digestive tract and metabolism [14, 18, 19], and the latter has been correlated with higher severity scores use [14, 20]. Furthermore, a preliminary study showed that neonates in NICUs were frequently exposed to potentially noxious excipients [21]. The present study aimed to describe the drugs prescribed to different groups of neonates hospitalized in a NICU, and to analyze off-label use and harmful potential of drugs, in terms of its potential risks.

\section{Methods}

\section{Subjects and methods}

This was a retrospective cohort study on drug use at a NICU with neonate inpatients, conducted over a six-month period in a tertiary-level facility [22].

The inclusion criteria were: neonates, aged $\leq 28$ days, admitted in the NICU for more than 24 hours, who received pharmaceutical products to treat or prevent specific diseases and had completed electronic clinical records at the time of the study. Patients with incomplete clinical data, incomplete prescriptions or prescriptions containing only vaccines, blood products, parenteral nutrition, silver nitrate eye drops or intramuscular administration of phytomenadione in the delivery room, or intravenous hydration, were excluded.

Medicine information leaflets or the electronic leaflet database of the ANVISA were used to identify the excipients present in the formulations.

\section{Data collection}

Prescription data and other information were obtained from the electronic medical records of the patient relating to his NICU stay. A specific form was used to collect patient's information: gestational age (GA), birth weight (BW), BW adequacy, gender, date of birth, Apgar score at 1' and 5', diagnoses and data on the prescribed formulations: active ingredient, pharmaceutical company, pharmaceutical form, route of administration, daily dose, and beginning and end of treatment and the observed outcome (discharge, transfer or death). No data was recorded regarding intravenous hydration, vaccines, blood products, parenteral nutrition composition, use of silver nitrate eye drops or intramuscular administration of phytomenadione to patients in the delivery room. These last two drugs are of compulsory use in all neonates in the delivery room in Brazil, so they were not considered in the analysis [17].

\section{Classification of the drugs and excipients}

Drugs were codified in accordance with the Anatomical Therapeutic Chemical classification [23] and were classified, as proposed by Neubert et al. [24], as follows: a) licensed (L)-drugs with registration issued by the ANVISA; b) unlicensed (UL)-drugs with no registration; or c) off-label (OL) use-use not detailed in the information leaflets, including therapeutic indication, patient age, strength (dosage), pharmaceutical form and route of administration categories. This classification was based on the information present in the information leaflets and on the websites http://www.anvisa.gov.br/datavisa/fila_bula/index.asp [25] and http://www.bulas.med.br/ [26].

Drugs were also analyzed according to their recommendations for use in neonates based on the British National Formulary for Children 2012-2013 (BNFC) [13] and the Thomson Micromedex@ database [27]. Harmful excipients (adverse reactions reported) were categorized in accordance with Lass et al. [28] and Souza Jr et al. [21]. The composition of prescription formulations were determined from the information leaflets of the medicine, identified on the ANVISA database. 


\section{Data processing and statistical analysis}

Study subjects were classified as extremely preterm ( $<28$ weeks of GA; EPN), preterm (28-36 weeks of GA; $\mathrm{PN}$ ) and term neonates ( $>37$ weeks of GA; TN); PN were subdivided into: a) 28-30 weeks of GA, b) 31-33 weeks of GA and c) 34-37 weeks of GA [2].

The exposure variables analyzed were: unlicensed medicines (UL), off-label use (OL) and exposure to harmful excipients. Exposure to drugs and harmful excipients was expressed as the exposure rate (ER), in which the numerator was the number of neonates exposed, at least to the drug or excipient concerned, one or more times, and the denominator was the total number of neonate-days at risk of using a drug or an excipient. The ER made it possible to evaluate the exposure of newborn infants to each drug or excipient. All data were stored and analyzed in Excel for Windows (version 7) and in the Statistical Package for the Social Sciences (version 18), using simple descriptive analysis; ANOVA and nonparametric tests (Mann-Whitney U and Kruskal-Wallis) were used for quantitative variable distribution, and Pearson's chisquare test for nominal variables classified according to GA, with a significance level of $p<0.05$.

This study was approved by the Research Ethics Committee of the Health Department of the Federal District, Brazil (approval No. 021/2012, of January 23, 2012). The informed consent was not applied because it was dispensed by the ethics committee. This approval was based on the Resolution of the National Health Council No. 466/12 regarding the procedures of an observational and retrospective study, in which privacy and confidentiality of clinical data and the subjects involved were assured [29].

\section{Results}

\section{Characteristics of the neonates}

Patients were selected from a list issued by the nursing staff, containing 407 newborns hospitalized during the period, 206 of which were not included in the study (90 were not found in the system, 44 only received intravenous hydration, 37 with incomplete data and 35 of age $>28$ days). Thus, 201 neonates who were inpatients for over 24 hours, for whom medication prescriptions had been recorded in the electronic system, were included in the study. Of these, nine were subsequently excluded because their prescriptions only related to delivery room care. Thus, the studied sample was 192 neonates. Out of this total, 100 (52.1\%) were male, 133 (69.2\%) were born by cesarean delivery, 40 (20.8\%) had Apgar 5' less than 7 and 128 (66.6\%) needed to be resuscitated. The mean gestational age was $33.3 \pm 4.3$ weeks, and the majority of them were PN (75.0 \%). The mean birth weight was $1909.5 \mathrm{~g} \pm 886.0$; $39(20.3 \%)$ were small for their gestational age and 70 (36.5 \%) had a very low birth weight $(<1500 \mathrm{~g})$. The mean length of hospital stay was $18.8 \pm 18.1$ days, corresponding to a total of 3617 neonate-days. There was no significant variation in the average length of hospital stay among the subgroups of GA ( $p>0.05)$. The mortality rate was inversely proportional to the GA ( $\mathrm{p}>0.05)$ (Table 1 ).

The most frequent diagnosis was neonatal jaundice $(115 ; 59.8 \%)$ followed by respiratory distress (104; $54.1 \%)$, sepsis $(72 ; 37.5 \%)$, anemia $(56 ; 29.1 \%)$ and hyaline membrane disease (HMD) (42; $21.8 \%)$. The mean number of diagnoses varied depending on the GA and was higher among neonates with $\mathrm{GA}<31$ weeks $(p<0.05)$ with a higher frequency of jaundice, sepsis and HMD, while congenital heart disease, seizures and hydrocephalus were observed more frequently among the TN.

\section{Prescribed drugs and formulations}

During the study period, 3290 prescriptions were registered, with a median of 11 prescriptions/neonate (range: 1-103), with 103 formulations and 87 drugs. A total of 1725 drugs were prescribed, and the mean was 8.8 drugs/neonate $(S D \pm 6.1)$. The number of prescriptions, drugs and drugs/neonate were greater for neonates with GA $<31$ weeks $(p<0.05)$ (Table 1$)$.

According to the first level of the ATC classification, the highest risk to the neonates was exposure to systemic anti-infectives, with an exposure rate (ER) of 5.0 for every 100 neonates, followed by drugs that act on blood and blood-forming organs (ER 3.7), digestive tract and metabolism (ER 3.5), nervous system (ER 3.0), and respiratory system (ER 2.9). The ER varied with the GA and, thus, EPN were more exposed to drugs that act on the respiratory system (ER 4.2), whereas in the other GA groups, systemic anti-infectives were the drugs most frequently used, especially in the range of 31-33 weeks (ER 6.5). Neonates between 31 and 33 weeks had higher ER for drugs that act on the respiratory system (ER 5.5) and digestive tract (ER 4.4) than the other GA. Neonates with the GA greater than 34 weeks had a higher risk of exposure to drugs that act on the nervous system than the other GA groups. Preterm neonates with GA of 28-30 and 34-36 weeks were more exposed to drugs that act on blood and blood-forming organs: an ER of 4.4 and 3.6 for every 100 neonates, respectively.

According to the fifth level of the ATC classification, the most prescribed drugs were gentamicin $(n=110$; ER $=3.0)$; ampicillin $(n=108 ; \mathrm{ER}=2.9)$; heparin $(n=97 ; \mathrm{ER}=2.6)$; phytomenadione $(n=95 ; \mathrm{ER}=2.6)$; aminophylline $(n=94$; $\mathrm{ER}=2.5)$; fentanyl $(n=92$; ER $=2.5)$; multivitamins without minerals $(n=91 ; \mathrm{ER}=2.5)$; folinic acid $(n=83$; ER $=2.2)$; dobutamine $(n=75 ; \mathrm{ER}=2.0)$; and vancomycin $(n=61$; ER =1.6). Neonates with a GA less than 34 weeks had higher incidence of aminophylline, whereas neonates with GA of 34-36 weeks and TN had a greater exposure to gentamicin and fentanyl, respectively (Table 2). 
Table 1 Characteristics and prescription profile of neonates admitted to a NICU in Brazil

\begin{tabular}{|c|c|c|c|c|c|c|c|}
\hline & \multirow{2}{*}{$\begin{array}{l}\text { Extremely preterm } \\
\text { neonates (EPN) } \\
<28 \text { weeks }\end{array}$} & \multicolumn{3}{|c|}{ Preterm neonates (PN) } & \multicolumn{3}{|l|}{ Term neonates (TN) } \\
\hline & & 28-30 weeks & 31-33 weeks & 34-36 weeks & $\geq 37$ weeks & Total (n) & $p$-value* \\
\hline $\mathrm{N}$ & 23 & 34 & 48 & 39 & 48 & 192 & - \\
\hline Male (\%) & 43.5 & 50.0 & 58.3 & 53.8 & 50.0 & 52.0 & $0.804^{a}$ \\
\hline Cesarean delivery (\%) & 43.5 & 67.6 & 79.2 & 79.5 & 64.6 & 69.2 & $0.019^{\mathrm{a}}$ \\
\hline Discharge (\%) & 17.4 & 38.2 & 56.3 & 59.0 & 66.7 & 51.5 & $<0.001^{a}$ \\
\hline Transfer (\%) & 17.4 & 14.7 & 27.1 & 23.1 & 22.9 & 21.8 & $<0.001^{a}$ \\
\hline Deaths (\%) & 65.2 & 47.1 & 16.7 & 17.9 & 10.4 & 26.5 & $<0.001^{a}$ \\
\hline Survivors (\%) & 34.8 & 52.9 & 83.3 & 82.1 & 89.6 & 73.4 & $<0.001^{\mathrm{a}}$ \\
\hline APGAR 1' (mean, SD) & $6.0 \pm 2.7$ & $5.9 \pm 2.0$ & $6.5 \pm 1.8$ & $7.0 \pm 1.6$ & $6.8 \pm 2.0$ & $6.5 \pm 2.0$ & $0.139^{b}$ \\
\hline APGAR 5' (mean, SD) & $7.7 \pm 2.2$ & $7.9 \pm 1.3$ & $8.1 \pm 1.1$ & $8.5 \pm 1.0$ & $8.2 \pm 1.3$ & $8.1 \pm 1.3$ & $0.100^{\mathrm{b}}$ \\
\hline Resuscitation (\%) & 69.6 & 79.4 & 68.8 & 64.1 & 56.3 & 66.6 & $0.275^{a}$ \\
\hline $\begin{array}{l}\text { Birth weight } \\
\text { (mean, SD- g) }\end{array}$ & $804.0 \pm 164.0$ & $1078.4 \pm 268.6$ & $1681.4 \pm 276.1$ & $2244.5 \pm 594.1$ & $2983.7 \pm 585.6$ & $1909.5 \pm 886.0$ & $<0.001^{c}$ \\
\hline NICU stay (days) & $24.0 \pm 25.1$ & $24.2 \pm 19.5$ & $14.7 \pm 13.1$ & $18.0 \pm 15.0$ & $17.3 \pm 19.3$ & $18.8 \pm 18.2$ & $0.203^{b}$ \\
\hline Neonate-days & 552 & 824 & 706 & 705 & 730 & 3617 & - \\
\hline Prescriptions (mean, SD) & $23.6 \pm 24.4$ & $22.5 \pm 19.2$ & $13.3 \pm 12.3$ & $16.6 \pm 15.7$ & $14.1 \pm 18.6$ & $17.0 \pm 17.9$ & $0.019^{b}$ \\
\hline Drugs (mean, SD) & $11.5 \pm 6.0$ & $11.9 \pm 5.3$ & $6.9 \pm 4.9$ & $9.0 \pm 5.8$ & $7.1 \pm 6.9$ & $8.8 \pm 6.1$ & $<0.001^{c}$ \\
\hline $\begin{array}{l}\text { Drugs/prescription } \\
\text { (mean, SD) }\end{array}$ & $4.1 \pm 1.5$ & $4.2 \pm 1.4$ & $2.8 \pm 1.4$ & $3.8 \pm 1.8$ & $3.0 \pm 2.0$ & $3.4 \pm 1.7$ & $<0.001^{c}$ \\
\hline$>6$ drugs (\%) & 73.9 & 85.3 & 41.7 & 53.8 & 37.5 & 54.7 & $<0.001^{a}$ \\
\hline Exposure to UL (\%) & 26.1 & 20.5 & 10.4 & 2.6 & 8.3 & 11.9 & $0.030^{\mathrm{a}}$ \\
\hline Exposure to OL (\%) & 100 & 100 & 100 & 100 & 97.9 & 99.5 & $0.555^{\mathrm{a}}$ \\
\hline $\begin{array}{l}\mathrm{UL} \text { and } \mathrm{OL} / \text { prescription } \\
\text { (mean, SD) }\end{array}$ & $3.6 \pm 1.3$ & $3.5 \pm 1.3$ & $2.5 \pm 1.2$ & $3.3 \pm 1.5$ & $2.5 \pm 1.8$ & $3.0 \pm 1.5$ & $<0.001^{c}$ \\
\hline $\begin{array}{l}\text { Exposure to high-alert } \\
\text { medications (\%) }\end{array}$ & 82.6 & 97.0 & 60.4 & 69.2 & 64.5 & 72.4 & $0.002^{\mathrm{a}}$ \\
\hline $\begin{array}{l}\text { Number of high-alert } \\
\text { medications (mean, SD) }\end{array}$ & $2.6 \pm 1.4$ & $2.4 \pm 1.5$ & $2.1 \pm 1.1$ & $2.7 \pm 1.5$ & $2.7 \pm 1.5$ & $2.5 \pm 1.4$ & $0.561^{\mathrm{b}}$ \\
\hline $\begin{array}{l}\text { Exposure to harmful } \\
\text { excipients (\%) }\end{array}$ & 91.3 & 100.0 & 93.7 & 92.3 & 83.3 & 91.6 & $0.101^{a}$ \\
\hline $\begin{array}{l}\text { Formulations with harmful } \\
\text { excipients (mean, SD) }\end{array}$ & $4.5 \pm 2.1$ & $4.5 \pm 2.0$ & $3.2 \pm 1.6$ & $4.1 \pm 1.7$ & $3.8 \pm 2.2$ & $3.4 \pm 2.1$ & $0.001^{b}$ \\
\hline
\end{tabular}

SD standard deviation

${ }^{\text {aPearson's chi-square }}$

${ }^{\mathrm{b}}$ Kruskal-Wallis test

${ }^{\mathrm{c}}$ ANOVA

${ }^{*} p$-value $(<0.05)$

\section{Unlicensed drugs, off-label use, potentially harmful drugs and harmful excipients}

Among the 87 different drugs used on neonates, 15 (17.2\%) were unlicensed (UL), including magistral oral solutions (hydrocortisone acetate, folic acid, antimonium tartaricum, arginine, biotin, sodium benzoate, anhydrous caffeine, cyanocobalamin, tricalcium phosphate, furosemide, L-carnitine, pyridoxine, riboflavin and thiamine) and injectable alprostadil (500 $\mathrm{mcg}$ ), which is imported. These formulations were prescribed to 23 neonates (12.0\%), of whom 19 received only one unlicensed drug. Out of the 1725 drugs analyzed from
3290 prescriptions, $38(2.2 \%)$ were classified as UL and 1687 (97.8 \%) were licensed, of which 1358 were off-label use (OL). Among the OL categories, age was the most frequent, followed by dose, route of administration, dosage form and indication. In the OL category of age, neonates were most exposed to heparin (97; $50.5 \%$ ), fentanyl $(92 ; 47.9 \%)$ and multivitamins without minerals (91; $47.4 \%)$ (Table 3).

Of all the 3290 prescriptions, 3145 (95.6\%) included OL drugs and 370 (11.2 \%), UL drugs. Nearly all neonates were exposed to OL use (191; $99.5 \%$ ), and neonates of $\mathrm{GA}<28$ weeks had a higher frequency of exposure 
Table 2 Exposure rate (\%) of drugs most prescribed of neonates admitted to NICUs in Brazil

\begin{tabular}{|c|c|c|c|c|c|c|c|c|c|c|c|c|c|c|}
\hline \multicolumn{3}{|l|}{$\mathrm{GA}<28$ weeks } & \multicolumn{3}{|l|}{ GA 28-30 weeks } & \multicolumn{3}{|l|}{ GA 31-33 weeks } & \multicolumn{3}{|l|}{ GA 34-36 weeks } & \multicolumn{3}{|l|}{$\mathrm{GA} \geq 37$ weeks } \\
\hline & $n$ & $E R$ & & $n$ & $E R$ & & $n$ & $E R$ & & $n$ & $E R$ & & $n$ & $E R$ \\
\hline aminophylline & 22 & 3.99 & aminophylline & 29 & 3.52 & aminophylline & 36 & 5.10 & gentamicin & 28 & 3.97 & fentanyl & 23 & 2.77 \\
\hline phytomenadione & 19 & 3.44 & phytomenadione & 28 & 3.40 & ampicillin & 27 & 3.82 & ampicillin & 26 & 3.69 & heparin & 23 & 2.77 \\
\hline $\begin{array}{l}\text { multivitamins } \\
\text { without minerals }\end{array}$ & 18 & 3.26 & $\begin{array}{l}\text { multivitamins } \\
\text { without minerals }\end{array}$ & 27 & 3.28 & gentamicin & 27 & 3.82 & fentanyl & 21 & 2.98 & gentamicin & 18 & 2.17 \\
\hline folinic acid & 17 & 3.08 & heparin & 25 & 3.03 & dobutamine & 19 & 2.69 & $\begin{array}{l}\text { multivitamins } \\
\text { without minerals }\end{array}$ & 20 & 2.84 & ampicillin & 17 & 2.05 \\
\hline ampicillin & 16 & 2.90 & folinic acid & 24 & 2.91 & phytomenadione & 19 & 2.69 & phytomenadione & 19 & 2.70 & metamizole & 15 & 1.81 \\
\hline gentamicin & 16 & 2.90 & ampicillin & 22 & 2.67 & multivitamins $^{\mathrm{b}}$ & 18 & 2.55 & folinic acid & 18 & 2.55 & dobutamine & 15 & 1.81 \\
\hline fentanyl & 15 & 2.72 & gentamicin & 21 & 2.55 & $\begin{array}{l}\text { multivitamins } \\
\text { without minerals }\end{array}$ & 17 & 2.41 & heparin & 18 & 2.55 & ranitidine & 15 & 1.81 \\
\hline heparin & 15 & 2.72 & fentanyl & 19 & 2.31 & heparin & 16 & 2.27 & ranitidine & 18 & 2.55 & vancomycin & 12 & 1.45 \\
\hline pulmonary surfactant & 11 & 1.99 & pulmonary surfactant & 19 & 2.31 & folinic acid & 15 & 2.12 & dobutamine & 14 & 1.99 & domperidone & 11 & 1.33 \\
\hline meropenem & 10 & 1.81 & dobutamine & 18 & 2.18 & vancomycin & 15 & 2.12 & domperidone & 13 & 1.84 & alprostadil & 10 & 1.20 \\
\hline vancomycin & 10 & 1.81 & domperidone & 18 & 2.18 & fentanyl & 14 & 1.98 & metamizole & 12 & 1.70 & phenobarbital & 10 & 1.20 \\
\hline dobutamine & 9 & 1.63 & vancomycin & 16 & 1.94 & domperidone & 11 & 1.56 & multivitamins $^{b}$ & 11 & 1.56 & phytomenadione & 10 & 1.20 \\
\hline amphotericin B & 6 & 1.09 & meropenem & 14 & 1.70 & amikacin & 10 & 1.42 & pulmonary surfactant & 9 & 1.28 & folinic acid & 9 & 1.08 \\
\hline cefepime & 6 & 1.09 & multivitamins $^{\mathrm{b}}$ & 13 & 1.58 & pulmonary surfactant & 10 & 1.42 & epinephrine & 8 & 1.13 & amikacin & 9 & 1.08 \\
\hline domperidone & 6 & 1.09 & amikacin & 8 & 0.97 & ranitidine & 8 & 1.13 & furosemide & 8 & 1.13 & midazolam & 9 & 1.08 \\
\hline teicoplanin & 6 & 1.09 & amphotericin B & 8 & 0.97 & cefepime & 7 & 0.99 & vancomycin & 8 & 1.13 & $\begin{array}{l}\text { multivitamins } \\
\text { without minerals }\end{array}$ & 9 & 1.08 \\
\hline epinephrine & 5 & 0.91 & cefepime & 8 & 0.97 & metamizole & 6 & 0.85 & aminophylline & 7 & 0.99 & furosemide & 8 & 0.96 \\
\hline tricalcium phosphate & 5 & 0.91 & epinephrine & 8 & 0.97 & hydrocortisone & 6 & 0.85 & cefepime & 7 & 0.99 & epinephrine & 6 & 0.72 \\
\hline multivitamins ${ }^{\mathrm{b}}$ & 5 & 0.91 & omeprazole & 8 & 0.97 & omeprazole & 6 & 0.85 & omeprazole & 7 & 0.99 & meropenem & 6 & 0.72 \\
\hline ranitidine & 5 & 0.91 & tricalcium phosphate & 7 & 0.85 & epinephrine & 5 & 0.71 & amikacin & 6 & 0.85 & multivitamins $^{\mathrm{b}}$ & 6 & 0.72 \\
\hline ferrous sulfate & 5 & 0.91 & ranitidine & 7 & 0.85 & tricalcium phosphate & 5 & 0.71 & mineral oil & 6 & 0.85 & dexamethasone & 5 & 0.68 \\
\hline
\end{tabular}

$E R$ exposure rate per 100 neonates

avitamins $A, B_{2}, B_{3}, B_{5}, B_{6}, C, D, E$

vitamins $A, B_{1}, B_{2}, B_{3}, B_{5}, B_{6}, B_{8}, C, D_{2}, E$ 
Table 3 Brazilian license situation, indications for neonates and off-label use in neonates in Brazil

\begin{tabular}{|c|c|c|c|c|c|c|c|c|}
\hline & \multirow[b]{2}{*}{ n (\%) } & \multicolumn{3}{|l|}{ MICROMEDEX } & \multicolumn{3}{|c|}{ BNFC 2012-2013 } & \multirow[b]{2}{*}{ Most frequent drugs (neonates) } \\
\hline & & Indicated (\%) & Not (\%) & NI (\%) & Indicated (\%) & Not (\%) & NI (\%) & \\
\hline Licensed & $329(19.1)$ & 78.7 & 21.3 & - & 75.4 & 24.6 & - & $\begin{array}{l}\text { domperidone (59)a, }, \text { vancomycin (55), pulmonary } \\
\text { surfactant (49), phytomenadione (47), furosemide } \\
\text { (29), epinephrine (26) }\end{array}$ \\
\hline Unlicensed & $38(2.2)$ & 36.8 & 7.9 & 55.3 & 47.4 & - & 52.6 & $\begin{array}{l}\text { tricalciumphosphate }(18)^{\mathrm{b}, \mathrm{d}} \text {, alprostadil (2), biotin } \\
(2), \mathrm{L} \text {-carnitine (2), riboflavin (2), thiamine (2) }\end{array}$ \\
\hline Off-label & $1358(78.7)$ & 64.8 & 22.9 & 12.3 & 90.6 & 3.0 & 6.4 & \\
\hline Age & $869(50.4)$ & 55.6 & 33.0 & 11.4 & 87.8 & 2.8 & 9.4 & $\begin{array}{l}\text { heparin }(97) \text {, fentanyl }(92) \text {, multivitamins without } \\
\text { minerals }(91)^{\mathrm{b}} \text {, aminophylline }(87), \text { ranitidine } \\
(53) \text {, metamizole }(37)^{\mathrm{a}, \mathrm{d}}, \text { cefepime }(31)^{\mathrm{a}, \mathrm{d}}, \\
\text { omeprazole }(29)^{\mathrm{a}}\end{array}$ \\
\hline Dose/frequency & $345(20.0)$ & 82.9 & 1.7 & 15.4 & 98.8 & 1.2 & - & $\begin{array}{l}\text { gentamicin (110), ampicillin (108), } \\
\text { amikacin (36), vancomycin (15), midazolam (3), } \\
\text { ampicillin/sulbactam (5) }\end{array}$ \\
\hline Age, pharmaceutical form & $23(1.3)$ & 34.8 & 65.2 & - & 95.7 & 4.3 & - & $\begin{array}{l}\text { spironolactone (7), methadone (6), captopril (3), } \\
\text { propranolol (2), sildenafil (2) }\end{array}$ \\
\hline Age, route of administration & $29(1.7)$ & 48.3 & - & 51.7 & 51.7 & 48.3 & - & $\begin{array}{l}\text { multivitamins without minerals }(15)^{\mathrm{b}} \text {, } \\
\text { mineral oil }(14)^{\mathrm{b}, \mathrm{c}}\end{array}$ \\
\hline Route of administration & $61(3.5)$ & 96.7 & 3.3 & - & 96.7 & 3.3 & - & phytomenadione (59), nystatin (2) $)^{\mathrm{a}, \mathrm{c}}$ \\
\hline Age, form, route of administration & $14(0.8)$ & 100.0 & - & - & 100.0 & - & - & aminophylline (14) \\
\hline Age, dose/frequency & $8(0.5)$ & 100.0 & - & - & 100.0 & - & - & aminophylline (8) \\
\hline $\begin{array}{l}\text { Indication, pharmaceutical form, route } \\
\text { of administration }\end{array}$ & $6(0.3)$ & 100.0 & - & - & 100.0 & - & - & epinephrine (6) \\
\hline Age, indication, pharmaceutical form & $1(0.1)$ & 100.0 & - & - & 100.0 & - & - & acetylsalicylic acid (1) ${ }^{\mathrm{a}}$ \\
\hline Dose/frequency, pharmaceutical form & $2(0.1)$ & 100.0 & - & - & 100.0 & - & - & furosemide (1), levothyroxine (1) \\
\hline Total & $1725(100.0)$ & 66.8 & 22.3 & 10.9 & 86.8 & 7.1 & 6.1 & \\
\hline
\end{tabular}

NI No information

${ }^{\mathrm{a}}$ Not indicated by Micromedex

${ }^{\mathrm{b}}$ Not found in Micromedex

${ }^{c}$ Not indicated by BNFC

dNot found in BNFC 
to prescriptions including UL or OL drugs $(p<0.05)$ (Table 1).

Most drugs were indicated to neonates by both Micromedex and BNFC (66.8 \% vs. $86.8 \%$ ), however Micromedex showed a greater number of drugs not indicated or without information than BNFC (33.2 \% vs. $13.2 \%)$. The most used drugs that were not indicated or not found in Micromedex were acetylsalicylic acid, mineral oil, multivitamins without minerals, metamizole, nystatin and omeprazole. According to BNFC, the drugs without information were cefepime, domperidone, metamizole, mineral oil, nystatin and tricalcium phosphate (Table 3).

Almost all neonates (91.6\%) were exposed to the following harmful excipients: methylparaben (ER 4.2 for every 100 neonates), propylparaben (ER 4.2), polysorbate 80 (ER 3.0), propylene glycol (ER 2.9), saccharin (ER 2.2), benzyl alcohol (ER 2.0) sodium benzoate (ER 1.8), ethanol (ER 1.8) and benzalkonium chloride (ER 0.4). There was no association between the number of exposed individuals and the GA $(p>0.05)$, although the average number of formulations containing harmful excipients was higher for EPN than for the other subgroups $(p<0.05)$ (Table 1).

\section{Discussion}

This paper presents a detailed analysis of drug use in a NICU in Brazil, and it is a pioneer study in the country in this aspect. While the number of observations of clinical records considered here is high, it has limitations in terms of the external validity. Primarily, because of the descriptive methodology of a wide range of newborn categories, diseases and drugs. Also, due to the retrospective character of the study, an important amount of clinical files were excluded due to incomplete data. Finally, it is based on a single NICU; even though a reference facility in the public health system in the Federal District, and covering a large population with a general profile of attendance. The conditions that led to hospitalization were similar to those seen in other NICUs in Brazil [14] and in other countries [16, 30], among which jaundice, sepsis, anemia and hyaline membrane disease were the most prevalent [31]. The length of hospital stay and the number of drugs were greater than found in other studies [16, 30], but lower than reported in preterm neonates admitted to an NICU in Germany (11.1 drugs/patient) [2], and in the USA (11.8 drugs/ patient) [32].

According to ATC classification, systemic anti-infectives were the most prescribed therapeutic group, as observed in other settings [16, 30-32], with ampicillin, gentamicin and vancomycin predominating. Vancomycin use correlated more with empirical treatment of neonatal sepsis. Cefepime and meropenem use were also very frequent, despite not being considered routine second- choice antibiotics. In fact, issues have been raised in medical literature regarding their use in neonates [3]. Antibiotic use varies according to each NICU, and generally depends on criteria established by the local staff, as suggested by Liem et al [33] in a comparative study conducted in the Netherlands. Heparin and phytomenadione, respectively, were the drugs acting on blood and blood-forming organs that were most prescribed for $\mathrm{TN}$ and for those with $\mathrm{GA}<31$ weeks. Patients who received concomitant heparin and phytomenadione $(n=60)$ were greater than those receiving only heparin $(n=37)$ or phytomenadione $(n=35)$, thus suggesting that phytomenadione was used for treating heparininduced thrombocytopenia during the hospital stay in the NICU. Heparin use (50\%) was greater than in USA and Estonia (47.0\% and $17.5 \%$, respectively) $[15,16]$. Phytomenadione use was more frequent $(49.5 \%)$ than in Estonia (11.6\%) [16] and less frequent than in Germany (90.0\%) [2] and Ireland (81.1 \%) [30], possibly because these last two analyses may have included phytomenadione administered intramuscularly in the delivery room, among other protocol differences.

Among the drugs acting on the digestive tract and metabolism, multivitamins without minerals were the most frequent, especially in neonates with a GA of less than 31 weeks. This prescribing practice is based on known vitamin deficiencies (A, D and $\mathrm{E}$ ), which are common among premature babies. However, according to the BNFC 2012-2013, the toxic potential of these formulations should be considered when there is another source of supplementation, especially for vitamin A [13]. Domperidone, ranitidine and omeprazole were also widely used, for suspected gastric reflux disease, although such use is questioned by several authors who have taken the view that the evidence regarding the risks and benefits of these treatments is inconclusive[6, 7, 34]. Regarding cardiovascular drugs, dobutamine was the most prescribed (39.0\%), with a higher frequency than those found in studies conducted in Germany [2] and Estonia [16] (31.7 \% and $12.2 \%$, respectively). Its use was greater in neonates with GA of 28-34 weeks; in most cases associated with hemodynamic instability due to septic shock.

In the group of drugs for respiratory tract disorders, aminophylline and pulmonary surfactant were the most prescribed, respectively, for apnea of prematurity and hyaline membrane disease, in preterm neonates. Aminophylline use was different to the recommendations adopted by other countries and by the WHO [35], where caffeine is considered to be a more effective and safer alternative [2, 16, 36]. In Brazil, oral and parenteral caffeine formulations are not commercialized, which increases the risk and hinders the access to imported formulations, or the use of magistral preparations [20]. 
Unlicensed drug use was associated with metabolic bone disease, inborn errors of metabolism and patent ductus arteriosus cases, and also involved magistral preparations or imported drugs. The prescription rate containing unlicensed medicines $(12.0 \%)$ was similar to that found in a study from Italy [23], but lower than that found in Estonia (22.0\%) [16], possibly due to different concepts for an "unlicensed drug". The OL use, mainly with drugs that act on the digestive tract, and the nervous and respiratory system, was predominantly prescribed for the most immature neonates. The majority of the package leaflets had no information regarding the use in neonates, which may reflect an absence of clinical trials or outdated leaflets. Dose/frequency was the second most frequent category of OL use, providing a warning with regard to the risks of toxicity associated with the lack of reference pharmacokinetic studies on the target population. This was observed in relation to the antimicrobials ampicillin and gentamicin, for which the information leaflets recommended daily administration, whereas the prescriptions presented dosages and administration intervals varying according to the GA $[13,27]$, taking into account the renal immaturity of these patients [37]. It was also reported in relation to multivitamin use, in which twice the manufacturer's recommended dose was widely prescribed (12 versus 6 drops, daily), containing tocopherol acetate, an excipient associated with E-Ferol syndrome [21].

Drugs for the digestive tract and metabolism, for the nervous system, and the systemic anti-infective group comprised of more than $50 \%$ of off-label use, and were indicated for most neonates. The sources of information (information leaflet, Micromedex and BNFC) diverged in some cases. For example, domperidone was indicated for neonatal use by the manufacturer but not by other sources, which highlights the risk of extrapyramidal effects. Differences between BNFC and Micromedex were also observed: for example, Micromedex does not recommend omeprazole, ketamine and teicoplanin, while BNFC does. Another important observation is that no warnings regarding the maturity of the neonates were seen in the leaflets, except for gentamicin, vancomycin and multivitamins without minerals.

The analysis on the harmful potential of the drugs was based on their presence in the list published by ISMP [38]. Among the 15 high-alert medications identified, 93.3\% had off-label use, in particular drugs acting on the cardiovascular system and nervous system. Most of the neonates were exposed to these drugs, especially those of a lower GA. All high-alert medications were indicated for neonates, according to BNFC, but according to Micromedex, ketamine, methadone, metoprolol and norepinephrine have not been established as safe in this age group, and dopamine is a safer alternative for dobutamine [27]. Almost all the neonates, particularly the most immature of them, were exposed to formulations containing harmful excipients, especially parabens and polysorbate 80 , for which the long-term effects are unknown [39]. Exposure to these excipients was mainly through oral formulations of drugs of questionable use, such as multivitamins and domperidone, as reported in a previous study [21]. The simultaneous or prolonged exposition to potentially harmful excipients can be an additional disease burden to neonates in critical conditions, which warns of the risk of toxicity due to concomitant and sometimes prolonged use of drugs containing the same excipients. In general, comparison of data on OL use and UL obtained in different contexts is difficult, primarily due to different study designs and methods. For this reason, we chose to use the consensus of Neubert et al. (2008) [24], to achieve comparable data and enable a broad discussion on the points raised. The limitations of this critical analysis reflects the controversial categories compared; OL use and use of harmful drugs and High Alert Medications per se are not necessarily wrong, and should be considered in light of the clinical needs and the existence of safer alternatives. But, even considering some degree of inconsistence of literature, exemplified by discrepancies between BNFC and Micromedex information, some practices identified in Brazil by this study, such as the use of silver nitrate eye drops, oral formulations multivitamins, domperidone, aminophylline, and ranitidine prescription, represents a known and avoidable risk for neonates. The use of silver nitrate in newborns in the delivery room is being questioned in literature, due to its limited efficacy, risk of chemical conjunctivitis and suffering on part of the babies, but in Brazil it remains obligatory [40]. The absence of a specific policy for pediatric/ neonatology drug registration in Brazil reflects in some of the discrepancies between drug indication by the FDA and ANVISA, exemplified by the use of antiepileptics observed in a Brazilian study [41].

The authors consider this kind of study a contribution to the question about the needs of better drugs for neonates and of a more standardized use of them. Although depicting a profile of drug use in a NICU is important and useful, the heterogeneity and multiplicity of the clinical problems and stages of prematurity, allow different management among facilities, particularly in clinical situations where scientific evidence of drug efficacy is lacking. Studies that consider a single system (such as respiratory disease) or a single therapeutic group could result in a more reliable comparison. The context observed is characterized by drug use based on minimal scientific evidence, in terms of efficacy and safety, and with inappropriate formulations that therefore have questionable predictability. To improve this situation, it is necessary to fill the gaps in the fields of pharmacokinetics 
and pharmacodynamics on neonates, as well as to develop more adequate formulations and proper clinical trials on long-term safety, efficacy and neurodevelopmental outcomes of some of the commonly used off-label and unlicensed drugs related in this study. This situation is far from being solved, despite ongoing efforts. It might be possible to reduce its damage through consistent policies of the spreading of scientific evidence information, and by implementing appropriate conditions to apply this knowledge around the world.

\section{Conclusions}

3290 prescriptions were analyzed, corresponding to 192 neonates and 3617 neonates-day. The number of prescriptions and drugs was higher in neonates with GA $<31$ weeks. Anti-infectives for systemic use, blood, alimentary tract, and metabolism drug groups were more frequent; varying according to the GA. More immature neonates presented a higher frequency of exposition to unlicensed drugs (UL) and off label use (OL). Almost all the neonates, particularly the most immature ones, were exposed to formulations containing harmful excipients, especially parabens and polysorbate 80 . Exposure to these excipients was mainly through oral formulations of drugs of questionable use, such as multivitamins and domperidone.

The context issue is characterized by drug use based on minimal scientific evidence, in terms of efficacy and safety, and avoidable use of inappropriate formulations that therefore have questionable predictability.

\section{Abbreviations \\ ANVISA: Brazilian National Health Surveillance Agency; BNFC: British National Formulary for Children 2012-2013; BW: birth weight; EPN: extremely preterm neonate; GA: gestational age; HMD: hyaline membrane disease; ER: exposure rate; ISMP: Institute for Safe Medication Practices; NEC: necrotizing enterocolitis; NICU: neonatal intensive care unit; OL: Off-label use; PN: preterm neonate; TN: term neonates; UL: unlicensed; VLBW: very low birth weight.}

\section{Competing interest}

The authors declare that they have no personal financial relationship with the sponsoring organizations, nor are there any other potential conflicts of interest.

\section{Authors' contributions}

This work is part of the doctorate thesis of AS Jr, for the Doctoral Program on Development and Technological Innovation in Drugs (Federal University of Ceará), who is a pharmacist, masters in clinical pharmacy and working in a pediatric hospital as a hospitalar pharmacist. AS Jr conceived the study, wrote the study protocol and collected the data. AS Jr, HC, DS wrote the first draft of the manuscript. AS Jr carried out the statistical analyses. LR, MM, MV made important contributions to the writing of the paper. DS supervised the analyses. All investigators reviewed and contributed to the manuscript; all authors read and approved the final manuscript.

\section{Acknowledgements}

This study was supported by grants from the Institute of Health Science Research and Teaching Foundation (FEPECS). We would like to thank Felipe Freitas MD, at the Mother and Child Hospital of Brasilia, for his comments on an earlier draft of this article.

\section{Data sharing statement}

Access to the study data may be provided by the authors to other researchers upon request.

\section{Author details}

'Pharmacy Department, Mother and Child Hospital of Brasilia, Brasília, Federal District, Brazil. ${ }^{2}$ Doctoral Program in Development and Technological Innovation in Drugs, Federal University of Ceará, Fortaleza, Ceará, Brazil. ${ }^{3}$ Mother and Child Hospital of Brasilia, SGAS, Av. L2 Sul, Quadra608, Módulo A, Asa Sul, Brasília CEP 70203-900DF, Brazil. ${ }^{4}$ Postgraduate Programme in Pharmaceutical Sciences, Federal University of Ceará, Fortaleza, Ceará, Brazil. ${ }^{5}$ Federal University of Recôncavo da Bahia, Santo Antônio de Jesus, Bahia, Brazil. ${ }^{6}$ Mother and Child Health Department, Federal University of Ceará, Fortaleza, Ceará, Brazil. ${ }^{7}$ Neonatology Department, Mother and Child Hospital of Brasilia, Brasilia, Federal District, Brazil.

Received: 28 May 2015 Accepted: 13 January 2016

Published online: 21 January 2016

\section{References}

1. Choonara I. Unlicensed and off-label drug use in children: implications for safety. Expert Opin Drug Saf. 2004;3(2):81-3.

2. Neubert A, Lukas K, Leis T, Dormann H, Brune K, Rascher W. Drug utilisation on a preterm and neonatal intensive care unit in Germany: a prospective, cohort-based analysis. Eur J Clin Pharmacol. 2010;66(1):87-95.

3. Giacoia GP, Taylor-Zapata P, Zajicek A. Drug studies in newborns: a therapeutic imperative. Clin Perinatol. 2012;39(1):11-23.

4. Jain $L$. The conundrum of off-label and unlicensed drug usage in neonatology. J Pediatr(Rio J). 2012;6:449-51.

5. Cotten CM, McDonald S, Stoll B, Goldberg RN, Poole K, Benjamin Jr DK, et al. The association of third-generation cephalosporin use and invasive candidiasis in extremely low birth-weight infants. Pediatrics. 2006;118(2):717-22

6. Malcolm WF, Cotten CM. Metoclopramide, $\mathrm{H} 2$ blockers, and proton pump inhibitors: pharmacotherapy for gastroesophageal reflux in neonates. Clin Perinatol. 2012;39(1):99-109.

7. Terrin G, Passariello A, De Curtis M, Manguso F, Salvia G, Lega L, et al. Ranitidine is associated with infections, necrotizing enterocolitis, and fatal outcome in newborns. Pediatrics. 2012;129(1):e40-45.

8. Allegaert K, Langhendries JP, van den Anker J. Do we need neonatal clinical pharmacologists? Eur J Pediatr. 2013;172(4):429-35.

9. World Health Organization. Maternal, newborn, child and adolescent health. http://www.who.int/maternal_child_adolescent/en/. Accessed 22 Feb 2015.

10. European Society of Paediatric and Neonatal Intensive Care. Standards and Guidelines. http://espnic-online.org/Education/Standards-and-Guidelines. Accessed 22 Feb 2015.

11. Sociedade Brasileira de Pediatria. Neonatologia. http://www.sbp.com.br/sbpservicos/sbp-residente/biblioteca/biblioteca-neonatologia/. Accessed 22 Feb 2015

12. Reuters T. Neofax 2011, 24th ed. Montvale, NJ: Thomson Reuters/Physicians Desk Reference, Inc.; 2011.

13. British Medical Journal. British National Formulary for Children 2012-2013. London: RPS Publishing; 2012.

14. Carvalho CG, Ribeiro MR, Bonilha MM, Fernandes Jr M, Procianoy RS, Silveira RC. Use of off-label and unlicensed drugs in the neonatal intensive care unit and its association with severity scores. J Pediatr (Rio J). 2012;88(6):465-70.

15. Kumar P, Walker JK, Hurt KM, Bennett KM, Grosshans N, Fotis MA. Medication use in the neonatal intensive care unit: current patterns and off-label use of parenteral medications. J Pediatr. 2008;152(3):412-5.

16. Lass J, Kaar R, Jogi K, Varendi H, Metsvaht T, Lutsar I. Drug utilisation pattern and off-label use of medicines in Estonian neonatal units. Eur J Clin Pharmacol. 2011;67(12):1263-71.

17. Brasil, MS, SAS, DAPE. Newborn health care: a guide of health professionals, 2nd edn. 2012. http://bvsms.saude.gov.br/bvs/ publicacoes/atencao_saude_recem_nascido_profissionais_v1.pdf. Accessed 22 Feb 2015.

18. Santos DB, Clavenna A, Bonati M, Coelho HL. Off-label and unlicensed drug utilization in hospitalized children in Fortaleza, Brazil. Eur J Clin Pharmacol. 2008;64(11):1111-8. 
19. Dos Santos L, Heineck I. Drug utilization study in pediatric prescriptions of a university hospital in southern Brazil: off-label, unlicensed and high-alert medications. Farm Hosp. 2012;36(4):180-6.

20. Coelho HL, Rey LC, Medeiros MS, Barbosa RA, Cruz Fonseca SG, Costa PQ. A critical comparison between the World Health Organization list of essential medicines for children and the Brazilian list of essential medicines (Rename). J Pediatr (Rio J). 2013;89(2):171-8.

21. Souza Jr A, Santos D, Fonseca S, Medeiros M, Batista L, Turner M, et al. Toxic excipients in medications for neonates in Brazil. Eur J Pediatr. 2014;173(7):935-45.

22. Regional de Saúde da Asa Sul. http://www.saude.df.gov.br/sobre-a-secretaria/ hospitais-e-regionais/264-regional-de-saude-da-asasul.html. Accessed 22 Feb 2015.

23. Dell'Aera M, Gasbarro AR, Padovano M, Laforgia N, Capodiferro D, Solarino $\mathrm{B}$, et al. Unlicensed and off-label use of medicines at a neonatology clinic in Italy. Pharm World Sci. 2007;29(4):361-7.

24. Neubert A, Wong IC, Bonifazi A, Catapano M, Felisi M, Baiardi P, et al. Defining off-label and unlicensed use of medicines for children: results of a Delphi survey. Pharmacol Res. 2008;58(5-6):316-22.

25. Brasil, MS, ANVISA. Bulário Eletrônico. http://www.anvisa.gov.br/datavisa/ fila_bula/index.asp. Accessed 10 Sep 2013.

26. Sistemas Inteligentes em Saúde [http://www.bulasmed.br]. Accessed 10 Sep 2013.

27. Reuters T: Thomson Micromedex database. In. New York: Thomson Reuters; 2013. http://www-micromedexsolutions-com.ez1 1.periodicos.capes.gov.br/ micromedex2/librarian. Accessed 10 Sep 2013.

28. Lass J, Naelapaa K, Shah U, Kaar R, Varendi H, Turner MA, et al. Hospitalised neonates in Estonia commonly receive potentially harmful excipients. BMC Pediatr. 2012;12:136

29. Council NH: Resolution of the National Health Council No. 196/96. 2012. http://conselho.saude.gov.br/web_comissoes/conep/aquivos/resolucoes/23_ out_versao_final_196_ENCEP2012.pdf. Accessed 01 Dec 2015.

30. Kieran EA, O'Callaghan N, O'Donnell CP. Unlicensed and off-label drug use in an Irish neonatal intensive care unit: a prospective cohort study. Acta Paediatr. 2014;103(4):e139-142.

31. Chatterjee S, Mandal A, Lyle N, Mukherjee S, Singh AK. Drug utilization study in a neonatology unit of a tertiary care hospital in eastern India. Pharmacoepidemiol Drug Saf. 2007;16(10):1141-5.

32. Warrier I, Du W, Natarajan G, Salari V, Aranda J. Patterns of drug utilization in a neonatal intensive care unit. J Clin Pharmacol. 2006;46(4):449-55.

33. Liem TB, Krediet TG, Fleer A, Egberts TC, Rademaker CM. Variation in antibiotic use in neonatal intensive care units in the Netherlands. J Antimicrob Chemother. 2010;65(6):1270-5.

34. Pritchard DS, Baber N, Stephenson T. Should domperidone be used for the treatment of gastro-oesophageal reflux in children? Systematic review of randomized controlled trials in children aged 1 month to 11 years old. Br J Clin Pharmacol. 2005;59(6):725-9.

35. World Health Organization. Model Formulary for Children. Based on the second model list of essential medicines for children 2009. Genebra: WHO; 2010. p. 2010.

36. Henderson-Smart DJ, Steer PA. Caffeine versus theophylline for apnea in preterm infants. Cochrane Database Syst Rev. 2010;1:CD000273.

37. Fjalstad JW, Laukli E, van den Anker JN, Klingenberg C: High-dose gentamicin in newborn infants: is it safe? European journal of pediatrics 2013.

38. Institute for Safe Medication Practices. ISMP's List of high-alert medications. http://www.ismp.org/Tools/highalertmedications.pdf. Accessed 10 Sep 2013.

39. De Cock RF, Knibbe CA, Kulo A, de Hoon J, Verbesselt R, Danhof M, et al. Developmental pharmacokinetics of propylene glycol in preterm and term neonates. Br J Clin Pharmacol. 2013;75(1):162-71.

40. Moore DL, MacDonald NE, Canadian Paediatric Society ID, Immunization C. Preventing ophthalmia neonatorum. Paediatr Child Health. 2015:20(2):93-6.

41. Borges AP, Campos MS, Pereira LR. Evaluation of unlicensed and off-label antiepileptic drugs prescribed to children: Brazilian Regulatory Agency versus FDA. Int J Clin Pharm. 2013;35(3):425-31.

\section{Submit your next manuscript to BioMed Central and we will help you at every step:}

- We accept pre-submission inquiries

- Our selector tool helps you to find the most relevant journal

- We provide round the clock customer support

- Convenient online submission

- Thorough peer review

- Inclusion in PubMed and all major indexing services

- Maximum visibility for your research

Submit your manuscript at www.biomedcentral.com/submit
Biomed Central 